\title{
Career Potential of Future Expert
}

\author{
Oksana Petrovna Tsaritsentseva ${ }^{1}$ \\ ${ }^{1}$ FSEI HPE “Orenburg State Pedagogical University”, Russia \\ Correspondence: Oksana Petrovna Tsaritsentseva, FSEI HPE "Orenburg State Pedagogical University", \\ Sovetskaya str., 19, 460014 Orenburg city, Russia.
}

Received: November 1, 2014 Accepted: December 23, 2014 Online Published: March 16, 2015

doi:10.5539/ass.v11n7p259

URL: http://dx.doi.org/10.5539/ass.v11n7p259

\begin{abstract}
This article is devoted to description and analysis of individual career potential. Topicality of the problem and the degree of its readiness in the modern science are stated at the beginning of the article.

Notions of "career", career factors, career potential and inner resources of personality being a part of career potential structure due to their essence and structure are exposed and analyzed in represented work. Diagnostic program which gives an opportunity to study individual career potential is described in the article. Results of the research of individual career potential factor structure discovered through student's sampling are represented according to the described diagnostic program.

The article ends with empirical study conclusions, correlation of received results with theoretical grounds of the work and definition of the direction of further research.
\end{abstract}

Keywords: career, individual career potential, inner resources of personality, career success

\section{Introduction}

There is no doubt that questions of detection of career potential of future experts are topical at the present stage of society development. Increase of employer requirements to the skill level of employees, dynamic international co-operation, development of small and medium business, decay of some professions and rise of new ones all these factors, happening literally in several years, on the one hand broaden the range of optant professional choice. On the other hand if individual has low awareness of his/her own career potential there is a danger of inappropriate use and application of personal career resources as well as a danger of their inefficient operation that could lead to the recession of professional results and career satisfaction. (Zeer, 2009; Moll, 2012).

Taking into account this status of an expert in the stated social and economic environment, the question of relatively conscious career planning is a critical one. At the same time answer to this question is a psychological basis of personal self-fulfillment in professional sphere. Conscious career choice in its turn is possible only in case when the person is aware of his/her own career resources and can control them (Mogilevkin, 2007; Drozdova, 2014).

\section{Methodology}

\subsection{Theoretical Grounds of the Research}

In our work we consider career as polydimensional social and psychological phenomenon, constrained by goal-oriented activity of a person, which guarantees the feeling of successful professional self-fulfillment. Career is developed during all life periods of a person in the area of processes of self-determination, self-organization and personalization it is also determined by the development of self-reflectiveness. The choice of career assumes ambiguous vision of one and the same subject area by different people and conformed to cultural and social peculiarity of a specific society (Acbieva et al., 2008; Schneider, 2001). Thereby career is a process and a result of implementation of personal intentions, connected with social and professional sphere of the society (Tsaritsentseva, 2013).

Treating the term "career" this way and introducing the term "career potential" for scientific search we make our interpretation of this concept appropriate. We consider career potential as a possibility, ability of an individual to advance in social and professional sphere of the society, fully implementing career desires (Tsaritsentseva, 2013; Leontiev, 2011). Thus career potential is renewable autonomous total of inner personal resources and the system of their control, resulting in career success. 
It is evident that fulfillment of personal career potential is certainly connected to the career success. Success is generally accepted as an achievement being socially appreciated. Society decides whether the result of efforts of individuals, groups or organizations could be considered as a success or not (Dzhaneryan, 2008; Пушкарева и Мусин, 2014, Mamina, 2011). That is why in order to determine the indicator of career potential we turned to biographies of people, who achieved public recognition on a definite level of historical development.

On the other hand career success can be considered as a satisfaction of a life situation, subjective evaluation of one's achievements. This way we highlight inner, subjective criteria of successful career. And even in these circumstances we must pay attention to the fact that subjective sensation of successful career is nothing more but adequate and full exercise of the available resources and achievement of stated objectives (Kozhevnikova, 2003; Nezorenko, 2010). This fact is to influence public recognition or social and professional mobility. Thus, for example, an employee developing in a horizontal career type increases his/her professional skills, excelling his/her colleagues and gaining recognition in professional community; and an employee developing in vertical career type becomes a senior manager and receives public appraisal as well, but in this case it is an increase in earning etc. In that way subjective estimation of success is influenced by outer features which are signs of success for other people (salary, status, recognition).

Therefore, if career is a process and a result of implementation of personal intentions, connected to social and professional sphere, then successful career is formed by conscious and adequate control of one's own career potential while reaching the stated career objective. There are two obvious components of successful career; it is career potential and personal career strategy. Further we will take a better look at the career potential of a future expert.

In order to define and classify personal resources forming a sole structure of career potential we started with the analysis of factors influencing a career. The most ambitious studies of career choice determinants and career evolution were conducted in foreign countries in 70s-80s (Super; Betz \& Fitzgerald; Krumboltz; Mc Clelland; Winter, et al.). As for our country similar researches were conducted in the context of studying personal traits of a leader (Zhuravlev \& Terekhov; Moll; Kibanov; Fillipov; Sleptsov). Personal factors influencing professional career of public officers were also studied in Russia (Derkach \& Zazykin; Derkach \& Diachkov; Kataeva; Mogilevkin, 1998; et al.). In researches performed during the last decade there are classifications of factors influencing a career as well (Safonova, Mogilevkin, Shapovalov, Faller, \& Kleimenova - its only present-day researches). However, we need to pay attention to the fact that naming career determinants authors seldom mention the way a particular factor influences a career (Moll, 2012; Mogilevkin, 2007; Zhdanovich, 2008; Tsaritsentseva, 2013; Faller, 2008). Here is an example. We made a combined list of factors (Table 1) basing on the analysis of existing approaches to career determinants.

Table 1. Factors influencing personal career

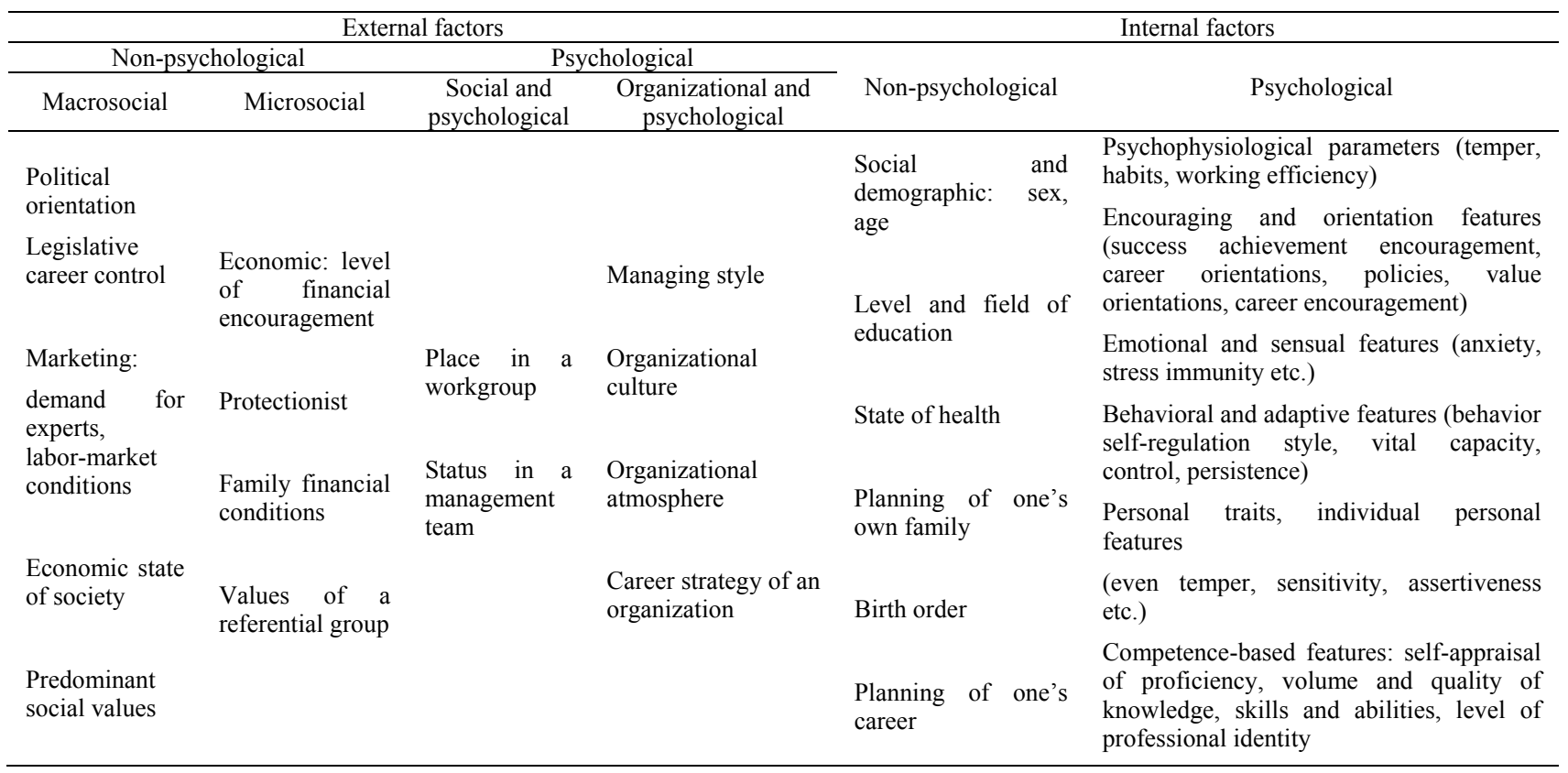


Thus, for example, external factors should be taken into consideration in career plan, but shouldn't be included in the notion of individual career potential, though their influence is evident. Internal factors (psychological as well as non-psychological) are included in individual career potential only partially. Some of these factors determine inclination to a definite career; some of them are parts of career potential structure and influence career success of an individual. For example, such factor as career orientation influences the choice of priority career course defining the most important elements of individual's professional life; therefore this factor doesn't influence career success directly, but determines definite career type. We can draw the same conclusion about such factors as: professional identity level, temper, general abilities, commutability, etc.

Therefore in order to single out from the majority of determinants those which could make a list of individual's career resources, integrated in a general structure of individual career potential, we analyzed and compared predominate personal traits in biographies of successful people from different fields of knowledge. We considered public recognition in different fields of science, art and public activity of the named people as a criterion for generation of purposive sample of biographies for the analysis. Biographies were selected by students of $5^{\text {th }}$ year of studying during the course "Psychological career accompaniment". There were the same instructions for all the participants: "To make biographies of famous people who achieved a success in a career". Afterwards biographies were subjected to content analysis. More than 50 biographies were processed and then gender balanced and structured in a unified format. By this analysis of biographies we sorted out sixteen features appearing in $60 \%$ of biographies: assertiveness; eccentricity; introversion; stress immunity; masculinity; versatility; achievement motivation; responsibility; self-discipline; high level of self-control; inclination for risk; high work efficiency; viability; self-confidence; analytical thinking; adequate I-image. After etymological and informative comparison of these sixteen features we shortened the list to seven invariants of career success. The list and description of career potential components are reflected in Table 2.

Table 2. Inner personal resources ensuring career success

\section{Inner resources defining individual's Individual's career potential indicators
career potential}

ability to be independent from external influence and assessments,

Assertiveness ability to control one's behavior without any assistance; eccentricity, nonconformism, singularity and uniqueness of views and opinions. Assertiveness is displayed in persuasion in one's efficiency based on self-esteem and one's importance (A. Bandura)

Masculinity presence of mental and behavioral features typical for man in contemporary society (ability to assert oneself, ability to act as a leader, courage, endurance, etc

Achievement motivation ability to attain stated goals despite any obstacles, striving for gaining the best result of all possible; inclination for risk, self-confidence, optimism

internality, attributing one's successes and fails to internal factors,

Responsibility subjective obligation to answer for deeds, actions and their consequences, readiness to admit consequences of one's choice.

High level of self-discipline arranging of personal time, tactical planning and strategic goal-setting. person's ability and readiness to act effectively under stress and hardships. Ability to perform hard work during long period of time

Viability with the same efficiency and productivity (as opposed to rapid fatigability, involuntary changing of a given activity); ability to recover soon and summon oneself in case of failure.

adequate system of person's notions about oneself, awareness of Adequate "I-image" one's strong and weak points, peculiarities of activities, realistic perception of one's abilities and capabilities, high (adequate) self-esteem, self-belief.

Theoretical pointes stated above provide the basis for our individual career potential diagnostic program (Figure 1). 


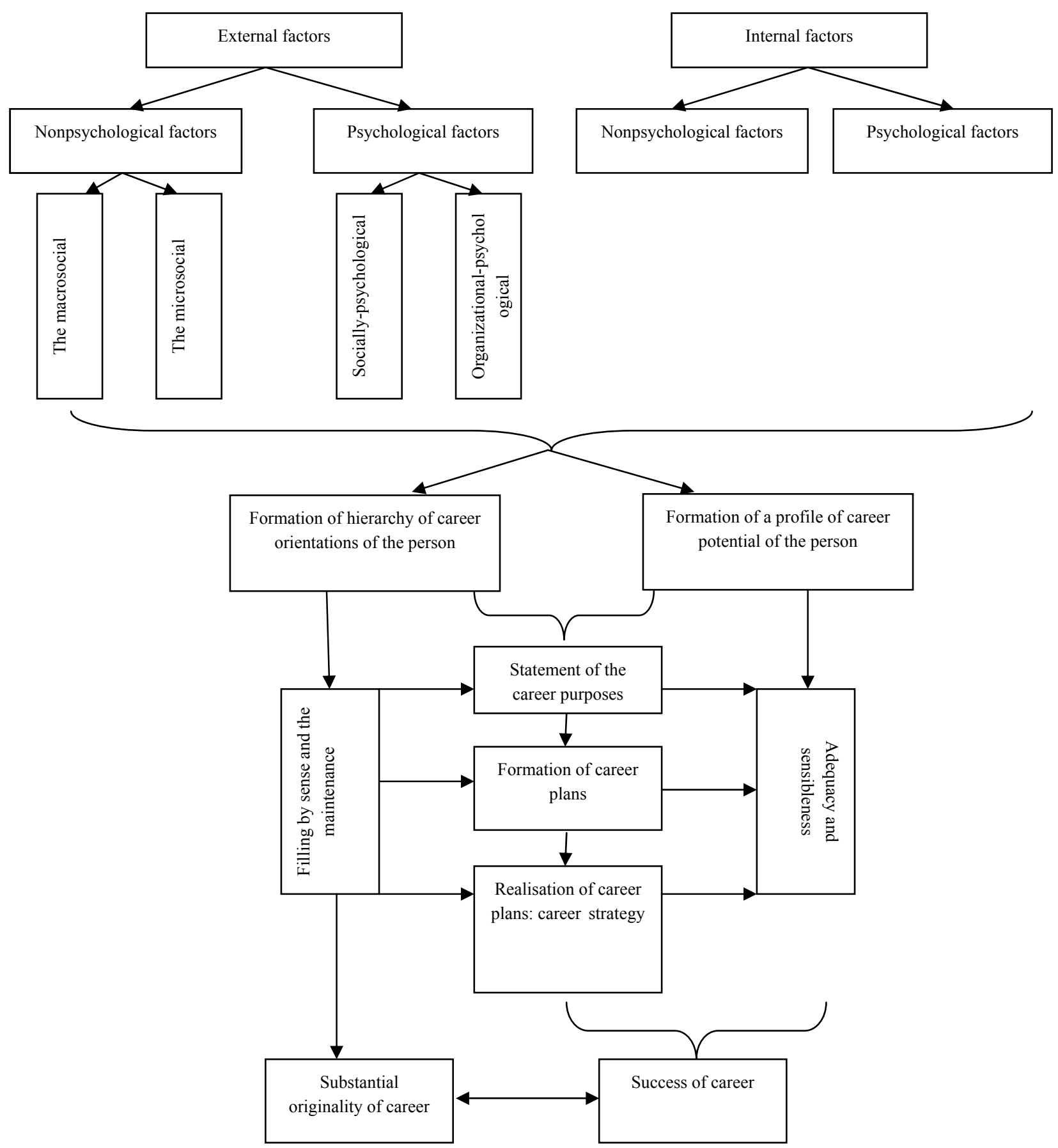

Figure 1. Structure of career of the expert

\subsection{Objective, Tasks and Methods of the Research}

The research described in this work was aimed at clarification of structure of individual career potential. In order to succeed in this objective we stated a number of tasks:

1. Define the content of notion "individual career potential" with the help of theoretical analysis.

2. Analyze and systematize inner personal resources composing the structure of individual career potential.

3. Select diagnostic tools, intended for studying inner resources composing the structure of individual career potential.

4. Conduct a survey over student's selection, subjecting the results to factor analysis.

5. Describe factor structure of individual career potential. 


\section{Outline prospective areas for further researches.}

On the basis of theoretical analysis of researches devoted to psychology of career and content analysis of biographies of successful people we developed a diagnostic program aimed at studying of inner personal resources composing the structure of individual career potential. Note that we regard career potential as renewable, autonomous total of inner personal resources and system of their control, resulting in career success.

For every set in this diagnostic program we chose methods appropriate to the feature of the resource under survey and permitting to study structural features of this phenomenon in their full scale. We suggest assessing individual career potential by this seven personal life features.

Diagnostic list includes: method of defining general and social self-efficacy (M. Sheer, J. Madduks; adaptation by A. V. Boyarintseva); individual psychological sex S. Bem (adaptation by O. G. Lopukhova); checklist of activity self-organization (E. Y. Mandrikova); viability test S. Maddy (adaptation by D. A. Leontiev, E. I. Rasskazova); questionnaire "Maturity of personality" Y. Z. Gilbukh. The correlation of examined resources, composing the structure of individual career potential and methods is represented in Table 3 (Gilbukh, 1994; Leontiev, \& Rasskazova, 2006; Lopukhova, 2001; Mandrikova, 2010; Rogov, 1998).

Table 3. The list of methods of individual career potential examination program

\begin{tabular}{ll}
\hline $\begin{array}{l}\text { Inner resources defining individual } \\
\text { career potential }\end{array}$ & Methods \\
\hline Assertiveness & $\begin{array}{l}\text { Method of defining general and social self-efficacy (M. Sheer, J. } \\
\text { Madduks; adaptation by A. V. Boyarintseva) }\end{array}$ \\
Masculinity & $\begin{array}{l}\text { Individual psychological sex S. Bem (adaptation by O. G. } \\
\text { Lopukhova) } \\
\text { "Achievement motivation" scale in questionnaire "Maturity of }\end{array}$ \\
Achievement motivation & $\begin{array}{l}\text { personality" (Y. Z. Gilbukh) } \\
\text { "Fixation" scale in a checklist of activity self-organization (E. Y. } \\
\text { Responsibility }\end{array}$ \\
Migh level of self-discipline & $\begin{array}{l}\text { Checklist of activity self-organization (E. Y. Mandrikova): general } \\
\text { indicator of method: regularity, persistence, self-discipline }\end{array}$ \\
Viability & $\begin{array}{l}\text { Viability indicator in viability test by S. Maddy (adaptation by D. A. } \\
\text { Leontiev, E. I. Rasskazova) } \\
\text { "Attitude to one's "I" in questionnaire "Maturity of personality" (Y. }\end{array}$ \\
\hline
\end{tabular}

1. Method of defining general and social self-efficacy (M. Sheer, J. Madduks; adaptation by A. V. Boyarintseva) allows determining how respondent subjectively evaluates his/her potential in objective activity and in sphere of communication which he/she (respondent) can actually use. The notion of self-efficacy allows evaluating the ability of people to realize their faculties and to realize the way how to use them efficiently. As a matter of fact self-efficacy is person's conviction in his/her ability to achieve a certain result applying certain efforts based on knowledge and former experience. The more efficiency the bigger results a person expects providing the same efforts applied. Introducing this notion A. Bandura underlined the fact that wise application of the most modest abilities could lead a person to high results. But on the other hand high potential is not always a guarantee of high results in case if a person due to some reasons does not believe in his/her ability to use this potential in a full scale and does not try to apply everything he/she gets from nature and from society. This method includes three scales: general self-efficacy, pragmatic self-efficacy and social self-efficacy (Mogilevkin, 2007).

2. Individual psychological sex S. Bem (adaptation by O. G. Lopukhova) in our case allows defining intensity of masculinity as a personal systemic quality. Presence of masculine sex role which is the basis of masculine scale combines personal display of individualism (self-reliance, independence, self-sufficiency, individualism, ambition) and display of individualism in relations with large number of people (standing upon one's believes, ability to assert oneself, forcefulness, ability to express one's point of view on public, necessity for rivalry). Masculine sex role also includes features of active, dominant and instrumental behavior type (inclination for sport, strong personality, analyticity, ability to lead, readiness for risk, easiness of making decisions, 
dominance/aggression, ability to act as a leader). Features from masculinity scale are essential for display of activity and achievement of success in macrosocial environment (Lopukhova, 2001).

3. Questionnaire "Maturity of personality" (Y. Z. Gilbukh) gives us information about 5 aspects composing maturity of personality: achievement motivation, attitude to one's "I" ("I" - concept); call of civic duty; life purpose; ability for psychological proximity to another person. We attributed certain scales of this method to different life features of personality. We treat maturity not only as a result of growing up, the quality depending mostly on age. This notion embraces persons body as well as personality to be exact the qualities connected to the mastering of moral standards, principals of interpersonal communication, behavior in a group, etc. (G. Gilbukh, 1994).

4. Checklist of activity self-organization (E. Y. Mandrikova) displays the degree of self-organization and self-regulation of activity by arranging one's time, plans making, goal-setting. This checklist also describes the degree of completeness of abilities to tactical planning and strategic goal-setting. Self-organization of activity is arranging of one's time, tactical planning and strategic goal-setting. The checklist has six scales. "Regularity" scale measures the degree of respondent's involvement in everyday tactical planning according to certain principals. "Purposefulness" scale measures the respondent's ability to focus on the goal. "Persistence" scale measures the respondent's inclination to apply will in order to finish the job begun and to streamline activity. "Fixation" scale measures the respondent's inclination to fixate on event organization structure planned beforehand, his/her sticking to a sharp schedule, rigidity in terms of planning. "Self-discipline" scale measures time orientation to the present. We attributed certain scales of this method to different life features of personality (Mandrikova, 2010).

5. Viability test by S. Maddy (adaptation by D. A. Leontiev, E. I. Rasskazova) allows making conclusion about person's ability to endure stressful situation, keeping inner balance without reducing activity's success. Applied aspect of viability is conditioned by the role this personal variable has in successful confrontation of personality to stressful situations mainly in professional sphere. According to the surveys viability is a key variable of a personality mediating the influence of stress factors (chronic as well) on somatic and mental health as well as on activity efficiency. Viability test gives opportunity to estimate ability and readiness of a person to act effectively under stress and hardships or his/her vulnerability to stresses and depressions. Viability is also a preventive factor of workability breach risk and of somatic and mental illnesses in stressful environment and it favors overcoming of situations of uncertainty and anxiety as well. Vigorous beliefs generate a kind of immunity to real sufferings. This test has three scales: involvement, control and assumption of risk (Leontiev, \& Rasskazova, 2006).

\section{Results}

Further studying of individual career potential factor structure we held in FSEI HPE "Orenburg State Pedagogical University". 84 students of the $4^{\text {th }}$ year: 36 males and 48 females at the age of 19-20 years took part in empirical study.

At the first stage we analyzed primary methodological distribution of results. Table 4 displays all scales composing the structure of every method we have chosen

Due to the fact that the majority of results are not close to the normal distribution we can make a conclusion about anomaly of distribution of received data. As a result of stated conditions average and standard deviation become meaningless, because they give wrong description of a variable. In our case values of median and interquartile range will be more significant because they give opportunity to describe the range including $50 \%$ of observations. We will not dwell upon the received results; we will only note strong and weak points of life features of personality composing the individual career potential structure, which we have sorted out in student sampling. Having correlated indexes of mode, median and intequartile range we can make a conclusion that there is a number of features requiring development so that career goals of these students would have been finally achieved as we have pointed out before that inner individual resources integrated in career potential can be renewed and controlled. First of all let's pay attention to the indexes of assertiveness, masculinity, achievement motivation, responsibility, self-discipline, viability and adequate "I-image". Such resources as assertiveness, viability, adequate "I-image", self-discipline are not sufficiently enough evident in students sampling. We will consider masculinity, achievement motivation and responsibility as strong points. Thus while achieving career goals future experts can face difficulties connected with lack of self-confidence, low ability to resist obstacles and stresses. Inability to arrange and plan their time and activity as well as inadequate idea about oneself and one's abilities are typical for them. These weak points could be balanced by resources which we stated as strong ones. Appealing to the content of these strong points we can underline that students are success 
and leadership oriented, they have personal features typical for masculine sex role in a society which is also a contribution to achievement of career goal and promptitude with complaisance as well. Therefore these features are not enough for the implementation of the idea. We can make the following conclusion: present-day graduates of Institutes of Higher Education are career oriented, aspire to high achievements, ready to execute orders but do not have enough inner abilities directly connected to attainment of career goals.

Table 4. Descriptive statistics of life features of personality composing individual career potential structure (Annotation 1)

\begin{tabular}{|c|c|c|c|c|c|c|c|c|c|}
\hline 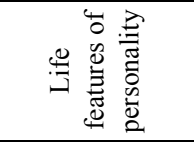 & $\begin{array}{c}\text { Scales composing } \\
\text { structure of methods } \\
\text { defining life features of } \\
\text { personality }\end{array}$ & $\bar{X}$ & $\mathrm{Me}$ & Mo & As & Ex & $\tilde{\sigma}$ & $\begin{array}{l}\text { Shapiro-Uilk } \\
\text { criterion (W) }\end{array}$ & $\begin{array}{c}\text { Normal distribution } \\
\text { assessment }\end{array}$ \\
\hline $\begin{array}{c}1 . \\
\text { Assertiveness }\end{array}$ & General self-efficacy & 144 & 146 & $\begin{array}{c}\text { Multip } \\
\text { le }\end{array}$ & -0.86 & 1 & 35 & $\begin{array}{c}0.92 \\
(\rho=0.01)\end{array}$ & Bimodal \\
\hline फ造 & Pragmatic self-efficacy & 111 & 109 & 109 & -0.06 & -0.12 & 36 & $\begin{array}{c}0.98 \\
(\rho=0.83)\end{array}$ & Normal \\
\hline 焉离 & Social self-efficacy & 36 & 39 & 42 & -0.68 & 0.56 & 10 & $\begin{array}{c}0.94 \\
(\rho=0.05)\end{array}$ & $\begin{array}{l}\text { Left asymmetry, } \\
\text { excess }\end{array}$ \\
\hline 2. Viability & Viability & 16 & 16 & 21 & 0.15 & -0.7 & 8 & $\begin{array}{c}0.96 \\
(\rho=0.27)\end{array}$ & Normal \\
\hline$\stackrel{3}{=0}$ & Risk assumption & 33 & 31 & 26 & 0.58 & -0.57 & 13 & $\begin{array}{c}0.94 \\
(\rho=0.04)\end{array}$ & $\begin{array}{l}\text { Right asymmetry, } \\
\text { excess }\end{array}$ \\
\hline 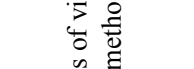 & Involvement & 28 & 29 & 30 & 0.11 & 0.04 & 10 & $\begin{array}{c}0.99 \\
(\rho=0.98)\end{array}$ & Normal \\
\hline 茑 & Control & 75 & 72 & 70 & 0.32 & -0.05 & 24 & $\begin{array}{c}0.97 \\
(\rho=0.05)\end{array}$ & Right asymmetry \\
\hline 3. Masculinity & Masculinity & 61 & 60 & 59 & -0.01 & -0.85 & 21 & $\begin{array}{c}0.97 \\
(\rho=0.40)\end{array}$ & Normal \\
\hline $\begin{array}{l}\text { 4. Achievement } \\
\text { motivation }\end{array}$ & Achievement motivation & 14 & 15 & 10 & 0.04 & -0.83 & 11 & $\begin{array}{c}0.97 \\
(\rho=0.54)\end{array}$ & Normal \\
\hline $\overrightarrow{0}$ & Call of civic duty & 14 & 14 & 14 & 0.21 & -0.71 & 11 & $\begin{array}{c}0.96 \\
(\rho=0.24)\end{array}$ & Normal \\
\hline 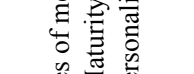 & Life purpose & 5 & 5 & 5 & 0.97 & 1.97 & 3 & $\begin{array}{c}0.92 \\
(\rho=0.01)\end{array}$ & $\begin{array}{c}\text { Right asymmetry, } \\
\text { excess }\end{array}$ \\
\hline 窇 & Maturity of personality & 33 & 32 & 33 & 0.41 & -0.54 & 26 & $\begin{array}{c}0.96 \\
(\rho=0.05)\end{array}$ & $\begin{array}{c}\text { Right asymmetry, } \\
\text { excess }\end{array}$ \\
\hline $\begin{array}{l}\text { 5. Adequate } \\
\text { "I-image" }\end{array}$ & Attitude to one's "I" & 14 & 13 & 5 & 0.59 & -0.65 & 14 & $\begin{array}{c}0.92 \\
(\rho=0.01)\end{array}$ & $\begin{array}{l}\text { Right asymmetry, } \\
\text { excess }\end{array}$ \\
\hline $\begin{array}{l}\text { 6. High } \\
\text { organizational } \\
\text { level }\end{array}$ & $\begin{array}{l}\text { General self-regulation } \\
\text { indicator }\end{array}$ & 95 & 98 & 98 & -1.06 & 1.51 & 29 & $\begin{array}{c}0.92 \\
(\rho=0.01)\end{array}$ & $\begin{array}{l}\text { Left asymmetry, } \\
\text { excess }\end{array}$ \\
\hline \multirow{4}{*}{ 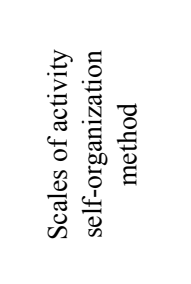 } & Regularity & 18 & 20 & 28 & -0.37 & -1.08 & 14 & $\begin{array}{c}0.91 \\
(\rho=0.005)\end{array}$ & $\begin{array}{l}\text { Left asymmetry, } \\
\text { excess }\end{array}$ \\
\hline & Persistence & 21 & 20 & 20 & 0.35 & -0.47 & 9 & $\begin{array}{c}0.95 \\
(\rho=0.16)\end{array}$ & Normal \\
\hline & Self-organization & 8 & 9 & 3 & -0.05 & -1.13 & 7 & $\begin{array}{c}0.92 \\
(\rho=0.01)\end{array}$ & Excess \\
\hline & Purposefulness & 32 & 32 & 32 & -1.16 & 2.75 & 9 & $\begin{array}{c}0.91 \\
(\rho=0.006)\end{array}$ & $\begin{array}{l}\text { Left asymmetry, } \\
\text { excess }\end{array}$ \\
\hline $\begin{array}{c}7 . \\
\text { Responsibility }\end{array}$ & Fixation & 20 & 21 & 25 & -0.45 & -1.04 & 7 & $\begin{array}{c}0.91 \\
(\rho=0.007)\end{array}$ & $\begin{array}{l}\text { Left asymmetry, } \\
\text { excess }\end{array}$ \\
\hline
\end{tabular}

\section{Discussion}

In this research we had more interest in factor model of the phenomenon than the intensity of student's life features. That is why further we conducted factorization. For factor analysis we chose principal components method which takes into account total as well as specific variance in every scale due to the fact that a set of scales is not homogeneous in its content. Rotation algorithm varimax was used.

After studying different factor models we chose a three-way model with $64 \%$ of interpretable dispersion. For significant factor loads we took loads with module over 0.45 . The following factors were defined as a result of three-way structure analysis (Table 5): 
Table 5. Three-way data structure of individual career potential methods

\begin{tabular}{cccc}
\hline Scale & \multicolumn{3}{c}{ Factor } \\
\cline { 2 - 4 } & 1 & 2 & 3 \\
\hline General self-efficacy & $\mathbf{0 . 7 4}$ & 0.25 & 0.31 \\
Pragmatic self-efficacy & $\mathbf{0 . 5 8}$ & 0.22 & $\mathbf{0 . 4 8}$ \\
Social self-efficacy & 0.38 & 0.32 & -0.13 \\
Viability & $\mathbf{0 . 7 2}$ & 0.17 & 0.04 \\
Risk assumption & $\mathbf{0 . 8 4}$ & 0.30 & -0.07 \\
Involvement & $\mathbf{0 . 8 4}$ & 0.09 & 0.09 \\
Control & $\mathbf{0 . 7 6}$ & 0.36 & 0.10 \\
Masculinity & $\mathbf{0 . 7 3}$ & 0.02508 & 0.20 \\
Achievement motivation & 0.30 & $\mathbf{0 . 8 3}$ & -0.04 \\
Call of civic duty & 0.31 & $\mathbf{0 . 7 1}$ & -0.14 \\
Life purpose & 0.13 & 0.44 & $\mathbf{0 . 4 7}$ \\
Maturity of personality & 0.002 & $\mathbf{0 . 7 8}$ & 0.36 \\
Attitude to one's "I" & 0.20 & $\mathbf{0 . 8 3}$ & -0.02 \\
General index of self-regulation & 0.22 & 0.04 & $\mathbf{0 . 5 8}$ \\
Regularity & $\mathbf{0 . 5 6}$ & 0.13 & 0.20 \\
Persistence & $\mathbf{0 . 5 3}$ & 0.23 & 0.38 \\
Self-discipline & -0.41 & 0.005 & $\mathbf{0 . 5 2}$ \\
Purposefulness & $\mathbf{0 . 4 7}$ & 0.16 & 0.44 \\
Fixation & 0.21 & -0.11 & $\mathbf{0 . 7 7}$ \\
Interpretable dispersion percentage & 31.80 & 18.37 & 13.74 \\
\hline
\end{tabular}

The first factor included such scales as general and pragmatic self-efficacy, viability, risk assumption, involvement, control, masculinity, regularity, persistence, purposefulness. Thus this factor embraces such personal features as assertiveness, readiness to overcome difficulties, inclination for risk, involvement in life process, activity, aspiration for tactic planning, ability to demonstrate efforts of will and purposefulness. We can assume that this factor's content is tactical pragmatic ability and readiness to achieve stated career objectives. This factor is connected to the quality of the process of achieving the goal.

The second factor included scales of achievement motivation, call of civic duty, maturity of personality and attitude to one's "I". This factor can be described by such personal features as self-fulfillment orientation, initiative, desire for achievements, social and team orientation, sociocentricity, adequate self-esteem, self-exactingness. Variables composing this factor define personal and motivational ability and readiness to achieve stated career objectives. The mentioned features can influence emotional involvement in the process of goal achievement and reflect self-confidence without infringing upon other people's interests.

The third factor is formed by such variables as pragmatic self-efficacy, life purpose, general index of self-regulation, self-discipline and fixation. Describing this factor we can mention such personal features as confidence in one's efficiency at solving different tasks, even temper, reasonableness, responsibility, ability to plan and structure activity. Apparently this factor conveys strategic ability to achieve stated career objectives. This factor appears in prospective and reasonable planning of one's career.

At the next stage we assessed individual career potential factor structure and left only 7 indexes, which we chose in the result of theoretical analysis (Table 3). Factor analysis results are represented in Table 6.

This factor structure slightly differs from the previous one, because variables which have been in different factors were united in another way in this analysis and only third factor became an exception. Here is a description of displayed factors. The first factor is represented by such variables as high level of self-discipline, displayed in the ability to goal-setting and planning, ability to confront difficulties and overcome obstacles and 
adequate self-esteem. The second factor can be characterized by achievement orientation and responsibility. The third factor is described by inner resources, reflecting self-confidence and manliness. It is evident that we can describe these factors as readiness to achieve career objectives $-1^{\text {st }}$ factor; a desire to achieve career objectives $2^{\text {nd }}$ factor; confidence in ability to achieve career objectives - third factor.

Table 6. Three-way data structure in chosen scales

\begin{tabular}{cccc}
\hline Scale & \multicolumn{2}{c}{ Factor } \\
& 1 & 2 & 3 \\
\hline Assertiveness & 0.39 & 0.41 & $\mathbf{0 . 5 3}$ \\
Masculinity & 0.36 & 0.04 & $\mathbf{0 . 8 2}$ \\
Achievement motivation & -0.10 & $\mathbf{0 . 8 8}$ & 0.10 \\
Responsibility & 0.11 & $\mathbf{0 . 8 9}$ & 0.04 \\
High level of self-discipline & $\mathbf{0 . 8 1}$ & 0.15 & -0.00 \\
Viability & $\mathbf{0 . 4 3}$ & -0.10 & -0.30 \\
Adequate "I-image" & $\mathbf{0 . 8 2}$ & -0.11 & 0.21 \\
Interpretable dispersion percentage & 26.50 & 25.83 & 21.88 \\
\hline
\end{tabular}

Therefore, despite the fact that variables were grouped differently in extended and short-cut factor analysis, there were a little difference in the content of displayed factor structures. According to the results of factor analysis we can make a conclusion that individual career potential is formed by inner resources, reflecting motivational and pragmatic readiness and ability (strategic and tactical) to achieve stated career objectives.

\section{Conclusions}

Thus, scientific novelty of the conducted research consists in reasoning the introduction of notion "career potential of individual" to psychology, description and reasoning of inner resources of personality, defining structure and content of career potential for its psychological diagnosis, representing general method of psychological diagnosis of individual career potential.

Summing up the conducted research we can make a conclusion that individual career potential is a complex phenomenon, combining life features of different types. System of interconnections between inner resources of personality which we defined as structure component of career potential is well interpreted and quite stable to different methods of factor analysis.

Practical implications of the research is the fact that suggested diagnostic program gives an opportunity to fully reveal, assess individual career potential in the process of professional studying or personnel operations while solving tasks of professional orientations and professional studying. Besides on the basis of this individual career potential factor structure could be devised training programs of correction and development of this phenomenon at different stages of proffessionalization.

The results of this research require further studying by comparison of factor structure variants of used set of methods, revealed in greater samplings of better quality (for example, during the process of achievement or with respondents of other professions, etc.) Besides we consider the search of methods that could be more appropriate to such inner resources of personality as responsibility and adequate "I-image" to be promising.

Finally despite restrictions mentioned above we consider the results of our research favor the opportunity for operationalization of individual career potential of a person and offer the challenge of its diagnostics.

\section{References}

Akbieva, Z., Ternovskaya, O., \& Schneider, L. (2008). Career psychology and professional relevant behavior of expert. Moscow: Moscow Institute of Psychology and Sociology.

Drozdova, N. (2014, October). Psychological barriers as risk factor of infringement of personal and professional development of the student-psychologist. Modern educational space: risks and safety: Materials of the international scientifically-practical conference (pp. 94-97). Orenburg: OGPU.

Dzhaneryan, S. (2008). Psychology of professional self-consciousness. Rostov-on-Don: Publishing house of 
South Federal University.

Faller, O. (2008). Acmeological diagnosis of career growth potential of state officer (published dissertation summary for a degree of Candidate of Psychological sciences). Russia, Moscow, FSEI HPE Russian Academy of State Service of Russian Federation president.

Gilbukh, Y. (1994). Questionnaire Maturity of Personality. Kiev: Scientific and Practice Center "Psychodiagnostics and Differentiated Studying".

Kozhevnikova, E. (2003). Courses of targeted social and psychological aid for orientation at labor market. Vectors of development of contemporary Russia: Mater. II International theoretical and practical conference of young social scientists, Moscow, 24-28.

Leontiev, D. (2011). Potential of personality: structure and diagnostics. Moscow: Smysl M.

Leontiev, D., \& Rasskazova, E. (2006). Viability test. Moscow: Smysl M.

Lopukhova, O. (2001). Individual psychological sex: Adaptation of diagnostic method. Applied psychology, 3, 57-67.

Mamina, T. (2011). Specific character of lingvocognitive modeling of "career" scenario in the Russian language (published dissertation summary for a degree of Candidate of Philological sciences). Russia, Tomsk, SEI HPE Tomsk State University.

Mandrikova, E. (2010). Development of checklist of activity self-organization (OSD). Psychological diagnostics, $2,87-111$.

Mogilevkin, E. (2007). Career growth: diagnostics, technology, practice. Saint-Petersburg: Rech.

Moll, E. (2012). Management of manager career. Saint-Petersburg: Piter.

Nezorenko, T. (2010). Management of manager career. Moscow: Laboratoria knigi.

Pushkeriova, L., \& Musin, A. (2014). Reflexions about career (according to youth poll). Concept, 2 http://e-koncept.ru/2014/14518.htm

Rogov, E. (1998). Handbook of practicing psychologist (Vol. 2, 2nd ed.). Moscow: VLADOS.

Schneider, L. (2001). Professional identity. Moscow: MOSU.

Tsaritsentseva, O. (2013). Structurally-substantial features of career orientations at early stages of professionalisation. Modern researches of social problems, 7. http://dx.doi.org/10.12731/2218-7405-2013$7-64$.

Zeer, E. (2009). Psychology of professional growth. Moscow: Academy.

Zhdanovich, A. (2008). Perception of professional career by students studying one or two specialties. Pressing problems of career guidance and career adaptation, 6, 9-13.

Note

Note $1 . \overline{\mathrm{X}}$ - arithmetical mean; Me - median, Mo - moda; As - asymmetry; Ex - excess; IQR - quartile range.

\section{Copyrights}

Copyright for this article is retained by the author(s), with first publication rights granted to the journal.

This is an open-access article distributed under the terms and conditions of the Creative Commons Attribution license (http://creativecommons.org/licenses/by/3.0/). 